ISSN (online): 2722-2055 https://jurnal.umj.ac.id/index.php/AS-
AS-SYIFA: Jurnal Pengabdian dan Pemberdayaan Kesehatan Masyarakat

\title{
Edukasi Kesehatan Mengenai Pentingnya Perilaku Hidup Bersih dan Sehat (Phbs) dan Pola Makan Gizi Seimbang Di Kampung Lembah Duhur, Bogor
}

\author{
Health Education About the Important of Clean and Healthy Living \\ Behaviors (Phbs) And Balance Nutrition In Kampung Lembah Duhur, Bogor
}

\author{
Cut Alia Keumala Muda ${ }^{1}$, Rini Handayani ${ }^{1}$ \\ ${ }^{1}$ Program Studi Kesehatan Masyarakat, Fakultas Ilmu-Ilmu Kesehatan, Universitas Esa Unggul \\ *email Korespondensi: cut.alia@esaunggul.ac.id
}

\begin{abstract}
Abstrak
Penyakit tidak menular menular dan penyakit menular merupa kan masalah kesehatan penting di Indonesia. Upaya preventiv yang dapat dilaksanakan untuk terhindar dari penyakit tersebut adalah dengan melaku kan Perilaku Hidup Bersih dan Sehat (PHBS) dan melakukan pola makan gizi seimbang. Tujuan pengabdi an masyara kat ini adalah untuk memberikan infomasi kepada masyarakat di Kampung Lemah Duhur, Desa Gunung Sunder, Kecamatan Pamijahan, Bogor mengenai pentingnya PHBS dan pola makan gizi seimbang. Adapun kegiatan yang dilakukan berupa konsultasi dengan menggunakan media poster. Konsultasi berjalan kondusif dan antusiasme masyarakat cukup bagi. Pemberian konsultasi yang utama diberikan kepada masyarakat Kampung Lemah Dulur yang dilakukan pada hari minggu, 16 September 2018 pada puk ul 09.30-1 1 .30 WIB. Hasil yang diperoleh yaitu 9 responden \& J7,5\%) hipertensi, 3 responden (12,5\%) kolesterol dan 12 responden (50\%) sehat. Kedepannya diharapkan dapat dilakukan pemberi an informasi kepada masyarakat mengenai PHBS dan gizi seimbang secara rutin karena masyarakat merasa kegiatan ini harus sering dilaksanakan, materi yang disampaikan berrnanfaat dan penyampaiannya cukup mudah dimengerti.
\end{abstract}

Kata Kunci : Konsultasi, PHBS, Gizi Seimbang, Pola Makan, Poster

\begin{abstract}
Uncommunicable and Communicable disease is important problem in Indonesia. To prevent infected or being sick, we be to do preventive action as clean and healrhy living behaviors (PHBS) and balance nutrition. The aim of this activity is to givellf ormation to people in Kampung Lemah Duhur, Desa Gunung Bunder, Kecamatan Pamijahan, Bogor about the importance of clean and healthy living behaviors (PHBS) and balance nutrition. The activity was wand with consultation method which used posters. The consultation gived topeople in Kampung Lemah Dufur, wich held on 16 september 2018 from 09:30- JJ :30 was done smoothly and people enthusiastic are high. In the future, giving information about clean and healthy living behaviors (PHBS) and balance nutrition will carry out routinely.
\end{abstract}

Keywords : Consultation, PHBS, Balance nutrition, poster 
Volume. 2 No.1 tahun 2020

Mei 2021 - November 2021
ISSN (online): 2722-2055 https://jurnal.umj.ac.id/index.php/AS-

SYIFA

AS-SYIFA: Jurnal Pengabdian dan Pemberdayaan Kesehatan Masyarakat

\section{Pendahuluan}

Di Indonesia, jumlah penyakit menular masih cukup tinggi setiap tahunnya dan jumlah penyakit tidak menular semakin meningkat dari tahun ketahun (Kementerian Kesehatan Republik Indonesia, 2019). Berdasarkan hasil penelitian Kesehatan Dasar tahun 2018, revalensi penyakit menular dan tidak menular di Bogor lebih tinggi dibandingkan prevalensi se-Jawa Barat Kementerian Kesehatan Republik Indonesia, 2019). Mengonsumsi makanan dengan pola gizi seimbang. Dengan menerapkan Perilaku Hidup Bersih dan Sehat dan mengonsumsi makanan dengan pola gizi seimbang diharapkan dapat mencegah penyakit menular dan tidak menular.

Salah satu upaya untuk memberdayakan anggota rumah tangga agar tahu, mau dan mampu melaksanakan perilaku hidup bersih dan sehat serta berperan aktif dalam gerakan kesehatan di masyarakat adalah dengan Perilaku Hidup Bersih dan Sehat (PHBS) di rumah tangga. Persalinan ditolong oleh tenaga kesehatan, memberi bayi ASI Eksklusif, menimbang bayi dan balita, menggunakan air bersih, mencuci tangan dengan air bersih dan sabun, menggunakan jamban sehat, memberantas jentik di rumah, makan buah dan sayur setiap hari, melakukan aktivitas fisik setiap hari, tidak merokok di dalam rumah merupakan IO kegiatan yang dilakukan dalam PHBS rumah tangga yaitu (Kementerian Kesehatan Republik Indonesia, 2011).

Berdasarkan data Kementerian Ke tan Republik Indonesia tahun 2013 diketahui bahwa praktik PHBS di rumah tangga baru 55,6\%. Angka ini ja uh tertinggal dengan target tahun 2013, yaitu sebesar 65\%. Di Bogor, persentase rumah tangga yang melakukan praktik PHBS dari tahun 2017 hingga 2019 belum mencapai target, yaitu pada tahun 2017 sebanyak 64,2\% (target 67\%), tahun 2018 sebanyak 65,5\% (target 70), dan tahun 2019 sebanyak 65,8\% (target 72) (Dinas Kesehatan Kota Bogor, 2020).

Salah satu perilaku penting yang mempengaruhi keadaan gizi seseorang yaitu pola makan, yang akan mempengaruhi kesehatan individu dan masyarakat. Gizi yang tidak optimal berkaitan dengan kesehatan yang buruk, meningkatkan risiko penyait terinfeksi, dan penyakit tidak menular seperti penyakit kardiovaskular diabetes serta kanker. Menjaga keseimbangan gizi merupakan salah satu cara untuk mengatur pola makan yang baik. Gizi seimbang adalah susunan pangan sehari-hari yang mengandung zat gizi dalam jenis dan jumlah yang sesuai dengan kebutuhan tubuh, dengan memperhatikan prinsip keanekaragaman pangan, aktivitas fisik, perilaku hidup bersih dan memantau berat badan secara teratur dalam rangka mempertahankan berat normal untuk mencegah masalah gizi yang nantinya dapat menyebabkan terjadinya penyakit menular maupun penyakit tidak menular (Kementerian Kesehatan Republik Indonesia, 2014).

Oleh karena pentingnya PHBS dan pola makan gizi seimbang agar bisa menurunkan risiko terkena penyakit menular maupun tidak menular, tim tertarik melakukan pengabdian masyarakat dengan mengangkat tema pentingnya PHBS dan pola makan gizi seimbang. Tujuan pengabdian masyarakat ini adalah untuk memberikan infomasi kepada masyarakat di Kampung Lemah Duhur, Desa Gunung Bunder, Kecamatan Pamijahan , Bogor mengenai pentingnya PHBS dan pola makan gizi seimbang. 
Volume. 2 No.1 tahun 2020

Mei 2021 - November 2021
ISSN (online): 2722-2055 https://jurnal.umj.ac.id/index.php/AS-
AS-SYIFA: Jurnal Pengabdian dan Pemberdayaan Kesehatan Masyarakat

\section{Metode}

Kegiatan ini dilaksanakan pada tanggal 16 September 2018 di Kampung Lemah Duhur, Desa Gunung Bunder, Kecamatan Pamijahan, Bogor. Sasaran kegiatan ini adalah masyarakat yang mengikuti kegiatan pemeriksaan kesehatan di Kampung Lemah Duhur, Desa Gunung Bunder, Kecamatan Pamijaha, Bogor. Jumlah yang berpartisipasi sebanyak 24 orang. Bentuk kegiatan pengabdian masyarakat yang dilakukan adalah konsultasi. Konsultasi dilakukan dengan menggunakan media poster.

Setelah rnasyarakat melakukan pemeriksaan kesehatan, masyarakat akan diarahkan ke meja konsultasi. Konsultasi dilakukan dengan menanyakan kepada masyarakat yang datang mengenai hasil pemeriksaan kesehatan. Setelahnya tim akan bertanya mengenai keluhan yang sering terjadi dan kebiasaan masyarakat yang diduga bisa menyebab \& penyakitnya kambuh ataupun terjadi. Tim kemudian menyarankan tindakan pencegahan agar tidak terjadi kambuhnya penyakit yang diderita dengan mengaitkannya ke PHBS dan gizi seimbang. Jika ada masyarakat yang tidak sakit memberikan penjelasan mengenai pentingnya melakukan PHBS dan Gizi Seimbang guna mencegah terjadinya penularan penyakit menular maupun tidak menular. Setelah konsultasi dilakukan, tim menanyakan bagaimana pendapat masyarakat mengenai pelaksanaan pengabdian masyarakat dengan metode konsulatasi yang baru saja dilakukan. Dalam prosesnya analisis data dilakukan secara kualitatif dengan melakukan wawancara terkait kegiatan seperti kebermanfaatan, isi materi serta pelaksanaan konsultasi. Selain wawancara serta hasil observasi diketahui bahwa masyarakat cukup antusias dalam sesi konsultasi.

\section{Hasil dan Pembahasan}

Kegiatan ini dilaksanakan pada tanggal 16 September 2018 pada pukul 09.30-11.30 WIB. Bentuk kegiatan yang dilakukan adalah konsultasi kesehatan. Konsultasi merupakan pertukaran pikiran untuk mendapatkan hasil (saran, nasihat dan sebagainya) yang sebaikbaiknya (Kementerian Pendidikan dan Kebudayaan, no date). Konseling dapat juga diartikan pemberian bantuan kepada klien dalam bentuk wawancara yang menuntut adanya komunikasi, interaksi mendalam dan usaha bersama antara konselor dan konseli untuk mencapai tujuan konseling yaitu pemecahan masalah, pemenuhan kebutuhan ataupun perubahan tingkah laku atau sikap agar individu tersebut dapat mengatasi masalahnya (Rani, no date).

Konsultasi diawali dengan menanyakan hasil pemeriksaan kesehatan masyarakat. Hasil yang diperoleh yaitu 9 responden $(37,5 \%)$ hipertensi, 3 responden $(12,5 \%)$ kolesterol, dan 12 responden $(50 \%)$ sehat.

Setelah itu, dilakukan pemberian edukasi kepada masyarakat mengenai PHBS dan gizi seimbang. Pada penderita Hipertensi dan Kolesterol, edukasi yang diberikan lebih ditekankan pada pengontrolan pola makan dengan gizi seimbang. Hal ini dikarenakan beberapa yang mengflmi rtensi dan kolesterol menyatakan mereka sering mengalami kambuh. Pola makan yang tidak sehat merupakan salah satu penyebab timbulnya kembali penyakit tidak menular (Suryani, Isdiany and Kusumayanti, 2018). 
Volume. 2 No. 1 tahun 2020 Mei 2021 - November 2021 https://jurnal.umj.ac.id/index.php/ASSYIFA

AS-SYIFA: Jurnal Pengabdian dan Pemberdayaan Kesehatan Masyarakat

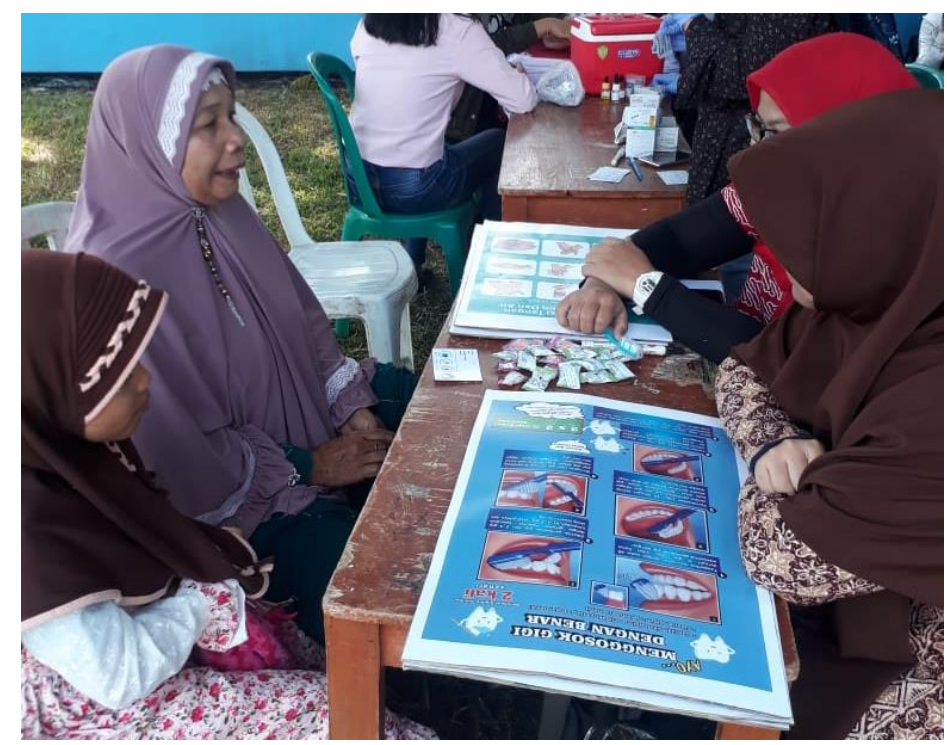

Gambar 1. Proses Konsultasi Dilakukan Pada Masyarakat

Dalam melakukan konsultasi, digunakan media bantu berupa poster. Poster bertujuan mempengaruhi seseorang agar tertarik atau mempengaruhi seseorang untuk bertindak akan sesuatu dengan bentuk pesan singkat dalam bentuk gambar (Astuti, 2018). Poster yang digunakan dalam kegiatan ini yaitu poster gizi seimbang, poster cuci tangan pakai sabun, poster cara menggosok gigi dengan benar, dan poster membuang sampah pada tempatnya.

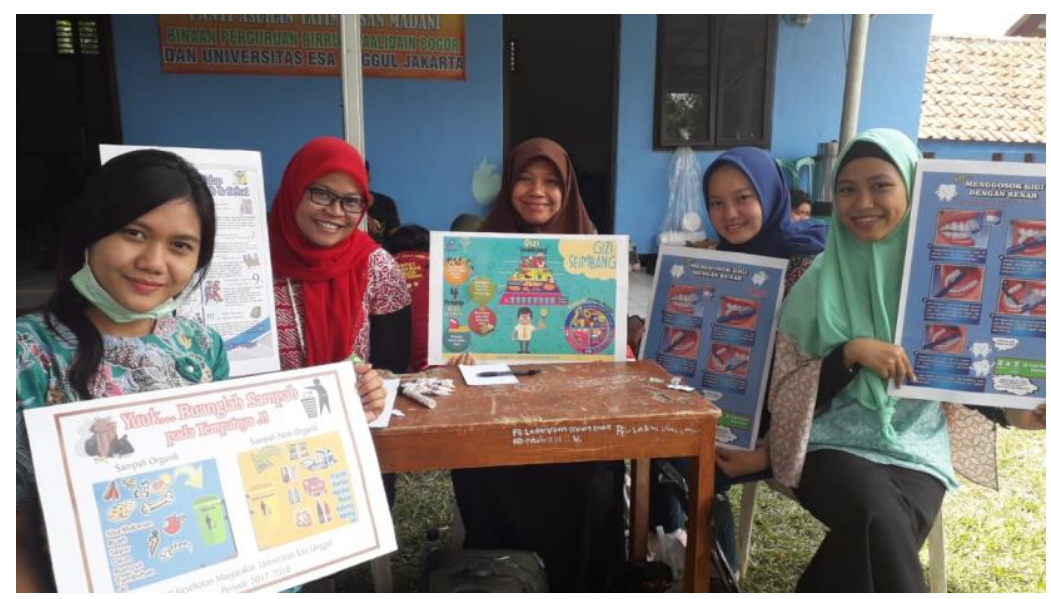

Gambar 2. Media Poster PHBS dan Gizi Seimbang

Antusias memasyarakat cukup tinggi dalam mengikuti kegiatan ini. Konsultasi terlaksana kondusif. Masyarakat sering bertanya dan mendengarkan dengan saksama mengenai apa yang disampaikan oleh konsultan. Konsultasi dianggap dapat memberikan cukup informasi mengenai cara menjaga kesehatan masyarakat. Masyarakat juga merasa terbantu dengan adanya poster. Poster dianggap dapat memberikan ilustrasi yang jelas mengenai materi yang disampaikan oleh konsulen. Masyarakat juga menganggap poster cukup informative dan menarik. 
ISSN (online): 2722-2055 https://jurnal.umj.ac.id/index.php/AS-
AS-SYIFA: Jurnal Pengabdian dan Pemberdayaan Kesehatan Masyarakat

Masyarakat merasa penting untuk dilakukannya konsultasi seperti ini di lingkungan mereka. Mereka menyampaikan bahwa fasilitas kesehatan berjarak cukup jau hs ehingga sulit untuk mereka mendapatkan informasi mengenai cara menjaga kesehatan, terutama kelompok lansia dan ibu hamil serta ibu menyusui. Oleh karena itu disarankan agar perlu dilakukan kegiatan pengabd ian masyarakat yang serupa dan berkesinambungan diwilayah ini.

Hasil yang diperoleh dari kegiatan ini $92 \%$ masyarakat menginginkan kegiatan ini dijadikan aktivitas rutin, $83 \%$ masyarakat merasakan kegiatan ini cukup bermanfaat, $79 \%$ masyarakat mengatakan bahwa materi dapat dimengert.i dengan baik, $71 \%$ masyarakat menginginkan materi ditambahkan dan lebih bervariasi

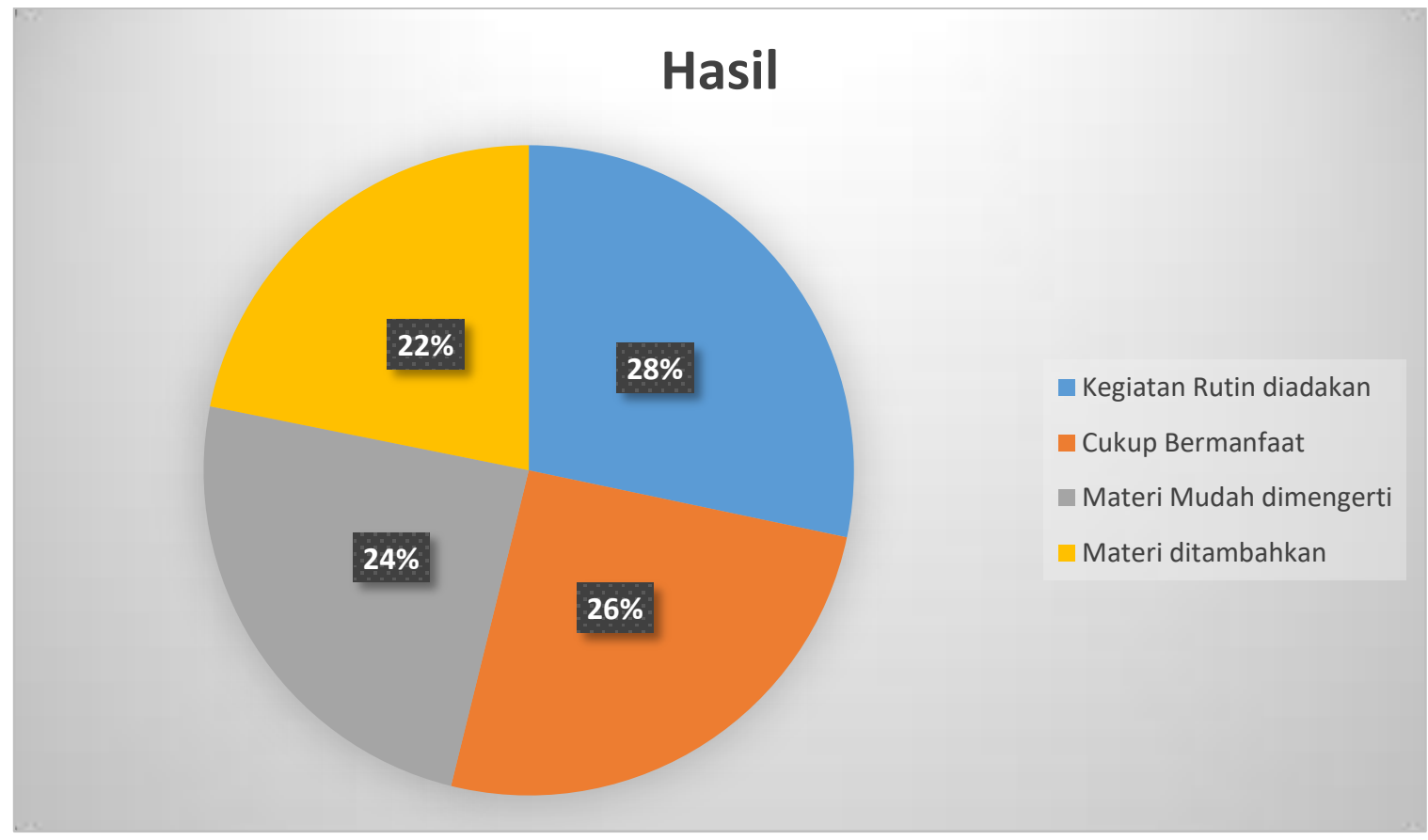

\section{Kesimpulan Dan Saran}

Kegiatan konsultasi kesehatan dengan memanfaatkan media poster dapat menambah pengetahuan masyarakat mengenai cara menjaga kesehatan melalui PHBS dan gizi seimbang. Disarankan agar dilakukan kegiatan serupa secara rutin di Kampung Lemah Duhur, Desa Gunung Bunder, Kecamatan Parnijahan, Bogor.

\section{Ucapan Terima Kasih}

Ucapan terima kasih penulis sampaikan kepada Ketua Kampung Lemah Duhur, Desa Gunung Bunder, Kecamatan Pamijahan, Bogor yang telah bersedia menjadi tempat kegiatan. Ucapan terima kasih juga disampaikan kepada Universitas Esa Unggul yang telah menfasilitasi kegiatan ini dilakukan. 
Volume. 2 No. 1 tahun 2020

Mei 2021 - November 2021
ISSN (online): 2722-2055 https://jurnal.umj.ac.id/index.php/AS-
AS-SYIFA: Jurnal Pengabdian dan Pemberdayaan Kesehatan Masyarakat

\section{Daftar Pustaka}

Astuti, H. (2018) PENGGUNAAN POSTER SEBAGAI MEDIA KOMUNIKASI KESEHATAN, Penggunaan Poster sebagai Media Komunikasi Kesehatan Komunikologi. Available at: https://komunikologi.esaunggul.ac.id/index.php/KM/article/view/187 (Accessed: 1 April 2021).

Dinas Kesehatan Kota Bogor (2020) Rencana Kerja dan Pendanaan Perangkat Daerah. Bogor.

Kementerian Kesehatan Republik Indonesia (2011) Peraturan Menteri Kesehatan Indonesia Nomor 226/MENKES/PER/XI/2011 Tentang Pedoman Pembinaan Perilaku Hidup Bersih dan Sehat (PHBS). Indonesia.

Kementerian Kesehatan Republik Indonesia (2014) Peraturan Menteri Kesehatan Republik Indonesia Nomor 41 Tahun 2014 Tentang Pedoman Gizi Seimbang. Indonesia.

Kementerian Kesehatan Republik Indonesia (2019a) Laporan Provinsi Jawa Barat: Riset Kesehatan Dasar Tahun 2019. Jakarta.

Kementerian Kesehatan Republik Indonesia (2019b) Laporan Riset Kesehatan Dasar Tahun 2018. Jakarta.

Kementerian Pendidikan dan Kebudayaan (no date) Arti kata konsultasi - Kamus Besar Bahasa Indonesia (KBBI) Online. Available at: https://kbbi.web.id/konsultasi (Accessed: 1 April 2021).

Rani, R. (no date) (15) (DOC) Konsultasi | Ranijah Rani - Academia.edu. Available at: https://www.academia.edu/21610144/Konsultasi (Accessed: 1 April 2021).

Suryani, I., Isdiany, N. and Kusumayanti, G. A. D. (2018) Dietik Penyakit Tidak Menular. Jakarta: Kementerian Kesehatan Republik Indonesia. 